\title{
Percentage* of Adults Aged $\geq 25$ Years Who Had Seen a Health Care Professional in the Past 12 Months and Who Easily Understood Information from Their Health Care Providers Most or All of the Time, ${ }^{\dagger}$ by Sex and Education Level — National Health Interview Survey,§ United States, 2017
}

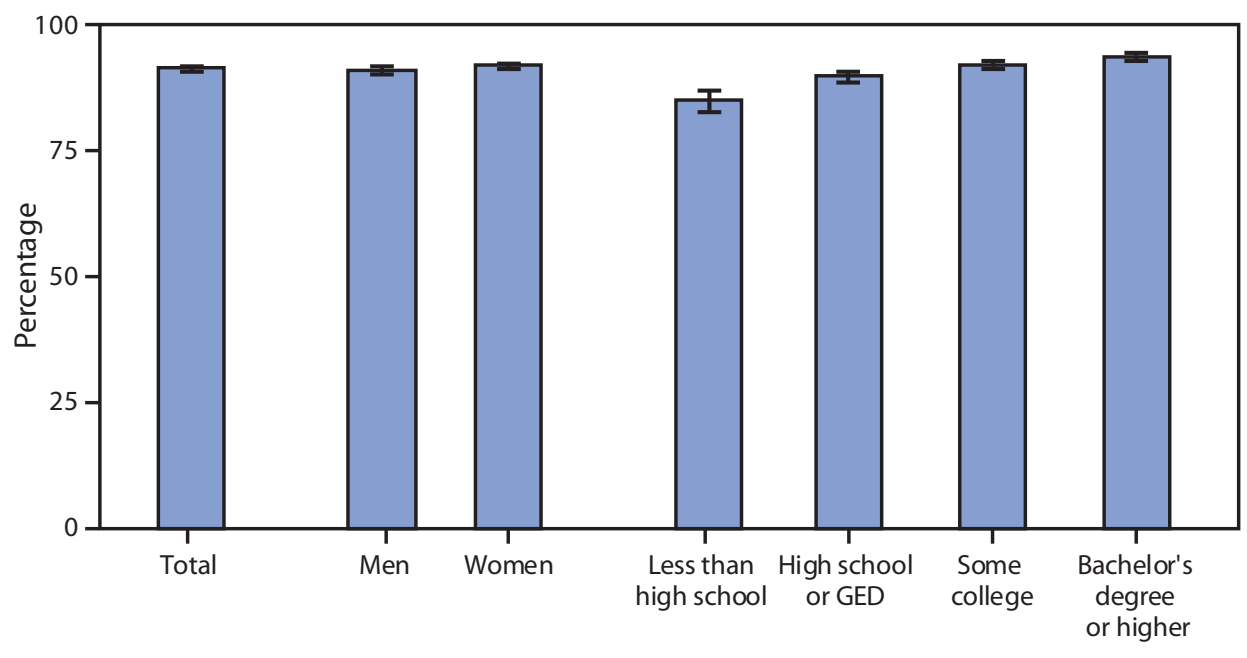

Sex

Education level

\begin{abstract}
Abbreviation: GED = general educational development certificate.
* With $95 \%$ confidence intervals indicated by error bars.

† Based on the response to survey questions that asked"How often did your health care providers tell or give you information about your health and health care that was easy to understand? Would you say always, most of the time, some of the time, or none of the time?"Response categories "always" and "most of the time" were combined and displayed. Adults who had not seen a doctor in the past 12 months were excluded from these estimates. $\S$ Estimates were based on household interviews of a sample of the civilian, noninstitutionalized U.S. population and were derived from the National Health Interview Survey Sample Adult component.
\end{abstract}

In $2017,91.6 \%$ of adults aged $\geq 25$ years easily understood information from their health care providers most or all of the time. The percentage of adults who easily understood health care information most or all of the time increased as education level increased. Adults who had completed a bachelor's degree or higher were the most likely to understand their health care providers at least most of the time (93.9\%), whereas those without a high school diploma were the least likely (85.2\%). Men (91.0\%) were somewhat less likely than women $(92.1 \%)$ to have easily understood information from providers most or all of the time.

Source: National Health Interview Survey, 2017. https://www.cdc.gov/nchs/nhis.htm.

Reported by: Alicia Jen; Carla Zelaya, PhD, czelaya@cdc.gov, 301-458-4164. 